\title{
Data Management Filenote
}

National Cancer Institute

\section{Source}

National Cancer Institute. Data Management Filenote. NCI Thesaurus. Code C115505.

A notation regarding the decisions, and/or clarification of any information pertaining to data management. 